\title{
Effectiveness of quality improvement strategies for coordination of care to reduce use of health care services: a systematic review and meta-analysis
}

\author{
Andrea C. Tricco PhD, Jesmin Antony MSc, Noah M. Ivers MD PhD, Huda M. Ashoor BSc, Paul A. Khan PhD, \\ Erik Blondal BSc, Marco Ghassemi MSc, Heather MacDonald MLIS, Maggie H. Chen PhD, Lianne Kark Ezer MSc, \\ Sharon E. Straus MD MSC
}

See related commentary, www.cmaj.ca/lookup/doi/10.1503/cmaj.141050

Competing interests: None declared.

Disclaimer: Sharon Straus is an associate editor with $C M A J$ and was not involved in the editorial decisionmaking process for this article.

This article has been peer reviewed.

Correspondence to: Sharon Straus, sharon.straus @utoronto.ca

CMAJ 2014. DOI:10.1503 /cmaj.140289

\begin{abstract}
Background: Frequent users of health care services are a relatively small group of patients who account for a disproportionately large amount of health care utilization. We conducted a metaanalysis of the effectiveness of interventions to improve the coordination of care to reduce health care utilization in this patient group.

Methods: We searched MEDLINE, Embase and the Cochrane Library from inception until May 2014 for randomized clinical trials (RCTs) assessing quality improvement strategies for the coordination of care of frequent users of the health care system. Articles were screened, and data abstracted and appraised for quality by 2 reviewers, independently. Random effects meta-analyses were conducted.

Results: We identified 36 RCTs and 14 companion reports (total 7494 patients). Significantly fewer patients in the intervention group than

in the control group were admitted to hospital (relative risk [RR] $0.81,95 \%$ confidence interval $[\mathrm{Cl}]$ 0.72-0.91). In subgroup analyses, a similar effect was observed among patients with chronic medical conditions other than mental illness, but not among patients with mental illness. In addition, significantly fewer patients 65 years and older in the intervention group than in the control group visited emergency departments (RR 0.69, 95\% Cl 0.54-0.89).

Interpretation: We found that quality improvement strategies for coordination of care reduced hospital admissions among patients with chronic conditions other than mental illness and reduced emergency department visits among older patients. Our results may help clinicians and policy-makers reduce utilization through the use of strategies that target the system (team changes, case management) and the patient (promotion of self-management).
\end{abstract}

$\mathrm{F}$ requent users of health care services represent a relatively small group of patients who account for a disproportionately large amount of health care utilization, including emergency department visits, ${ }^{1,2}$ hospital admissions and clinic visits. These patients are often of low socioeconomic status, ${ }^{3,4}$ have multiple medical, psychiatric and social disorders ${ }^{5,6}$ and have a high mortality. ${ }^{7}$ Frequent use of the health care system contributes to longer wait times and affects the quality of care., ${ }^{4,8}$

Disproportionate use of health care services by a segment of the population has been identified as a challenge in many countries, including Canada. $^{9-12}$ To encourage less resource-intensive care for frequent users, many efforts have been implemented. Some of these interventions, for example, have been designed specifically to transition health care utilization away from the hospital to other settings, such as community-based clinics. ${ }^{13}$

Much of the literature has focused on frequent users of emergency departments, with less focus on their use of the health care system in general. One systematic review identified a number of studies that assessed the effect of various interventions, including care coordination..$^{14}$ The authors concluded that case management and multidisciplinary teams were likely effective interventions to reduce emergency department visits.

Emergency department visits typically represent only a fraction of the cost burden on the health care system. There is a need to understand the impact of interventions aimed at reducing overall health care utilization, including hospital admissions. We conducted a systematic review and meta-analysis of the effectiveness of quality improvement strategies 
for care coordination for patients who are frequent users of the health care system.

\section{Methods}

We developed our protocol according to the PRISMA-P (Preferred Reporting Items for Systematic review and Meta-analysis Protocols) statement (available from the authors).

\section{Literature search}

The search strategies were developed by an experienced librarian and were reviewed by a second librarian using the Peer Review of Electronic Search Strategies checklist. ${ }^{15}$ A comprehensive search of MEDLINE, Embase and the Cochrane Library was conducted from inception until May 5, 2014, and was limited to adults and humans. The MEDLINE search strategy, outlined in Appendix 1 (available at www.cmaj.ca/lookup /suppl/doi:10.1503/cmaj.140289/-/DC1), was modified for the Embase and Cochrane Library searches with the use of appropriate medical subject headings (available upon request). We also searched trial registries and conference abstracts, scanned the reference lists of included studies and relevant reviews, contacted authors to request other potentially relevant studies, searched the 10 most related citations in PubMed for each included study and searched studies that referenced the included studies in Web of Science (i.e., forward citation searching).

\section{Study selection}

Before screening began, a calibration exercise was conducted to ensure high reliability in correctly selecting articles for inclusion. This exercise entailed screening a random sample of 75 citations (titles and abstracts) using Synthesi.SR (a proprietary online systematic review tool developed by the Joint Program in Knowledge Translation at St. Michael's Hospital, Toronto). The percentage agreement among these reviewers was quantified. After high agreement was achieved, each citation was screened by 2 authors using the predefined relevance criteria form. Discrepancies were resolved by discussion or the involvement of a third reviewer. The same process was followed for full-text review of potentially relevant articles identified through citation screening. When eligibility of a particular study was unclear, the study's authors were contacted for additional information.

Eligible studies were randomized clinical trials (RCTs) that assessed at least 1 of 5 predefined quality improvement strategies targeting adult patients (age $\geq 18 \mathrm{yr}$ ) who were frequent users of the health care system. The quality

\section{Box 1: Description of quality improvement strategies ${ }^{17}$}

\section{Care coordination}

Care coordination is the deliberate organization of patient care activities between 2 or more participants (including the patient) involved in a patient's care to facilitate the appropriate delivery of health care services. Organizing care involves the marshalling of personnel and other resources needed to carry out all required patient care activities; it is often managed by the exchange of information among participants responsible for different aspects of care. ${ }^{15}$

- Case management: The coordination of patient care, including diagnosis, treatment and ongoing patient management (e.g., arranging referrals, follow-up of test results, patient education, patient reminders) by an individual other than the primary care clinician. ${ }^{18}$

- Team changes: Changes to the primary health care team and how it functions, including routine patient visits with personnel other than the primary care physician, use of multidisciplinary teams and the expansion or revision of team members' professional roles. ${ }^{18}$

- Promotion of self-management: Providing equipment (e.g., home glucometers for patients with diabetes) or access to resources (e.g., electronic systems for transferring glucose measurements for patients with diabetes) and establishing joint goals to empower patients to manage their disease on their own. ${ }^{18}$

- Decision support: Operational process of adjustment for a system that generates regular feedback (from registry data) to clinical teams on guideline compliance or organizational support to facilitate other mechanisms for coordinating care. ${ }^{19}$

- Clinical information system: A quality improvement strategy encompassing numerous systems performing a wide variety of functions; distinguished from administrative information systems by the requirement for data entry or data retrieval by clinicians at the point of care. $^{20}$

\section{Additional components}

- Patient navigator: "Guide people through the health care maze, connecting them with the right doctors and helping them gain access to available therapies." 21

- Outreach activities: Assessment, education or follow-up conducted outside the clinic or hospital, in or near the patient's home.

\section{Other quality improvement strategies}

- Patient education: Educating patients about their disease, including prevention and treatment strategies. ${ }^{18}$

- Patient reminder systems: Reminding patients about upcoming appointments or important aspects of self-care (e.g., glucose monitoring for patients with diabetes). ${ }^{18}$

- Clinician education: Educating clinicians about a particular condition or illness that their patients might face, including strategies for prevention and treatment (e.g., based on clinical practice guidelines); may be conducted through conferences, workshops, distribution of educational materials and one-on-one educational outreach meetings (or academic detailing). ${ }^{18}$

- Clinician reminders: Reminding clinicians to look up patients' clinical information or to conduct specific tasks. ${ }^{18}$

- Audit and feedback: Generating summaries of clinic's or individual clinician's performance, which are transmitted back to the clinician. ${ }^{18}$

- Financial incentives: Providing clinicians with financial incentives for reaching pre-established goals or achievements; may also include incentives for patients or system-wide changes in reimbursement. ${ }^{18}$

- Continuous quality improvement: Using specific processes to identify quality problems, developing solutions, and implementing and evaluating changes; may include interventions, such as total quality management or plan-do-study-act. ${ }^{18}$

- Facilitated relay of information to clinicians: Transmitting clinical information from patients to clinicians by means other than the existing medical record. ${ }^{18}$ 
improvement interventions of interest, chosen to fill gaps in the "expanded chronic care model"16 and described in Box 1, ${ }^{15,17-21}$ are closely related to care coordination: case management, team changes, promotion of self-management, decision support, and clinical information systems. We also considered the effects of 2 additional components to an intervention: patient navigators and outreach activities.

Quality improvement strategies were compared with usual care, no intervention or other quality improvement strategies, as listed in Box 1. When more than one control arm was available in the studies, we chose the usual-care arm for inclusion in the analysis. Included studies had to report at least one of the eligible health utilization outcomes, specifically emergency department visits, hospital admissions or clinic visits; the proportion of patients was the primary outcome of interest. Studies written in any language, whether published or unpublished, and conducted at any point in time were eligible for inclusion.

\section{Data collection}

A data abstraction form was drafted and pilottested by 8 of us (A.C.T., N.M.I., H.M.A., P.A.K., E.B., M.G., H.M. and L.K.E.) working independently on a random sample of 5 articles. Data items we recorded were study characteristics (e.g., setting, type of study design), patient characteristics (e.g., population examined, mean age), quality improvement strategies examined and utilization outcomes examined. Two reviewers (A.C.T.,

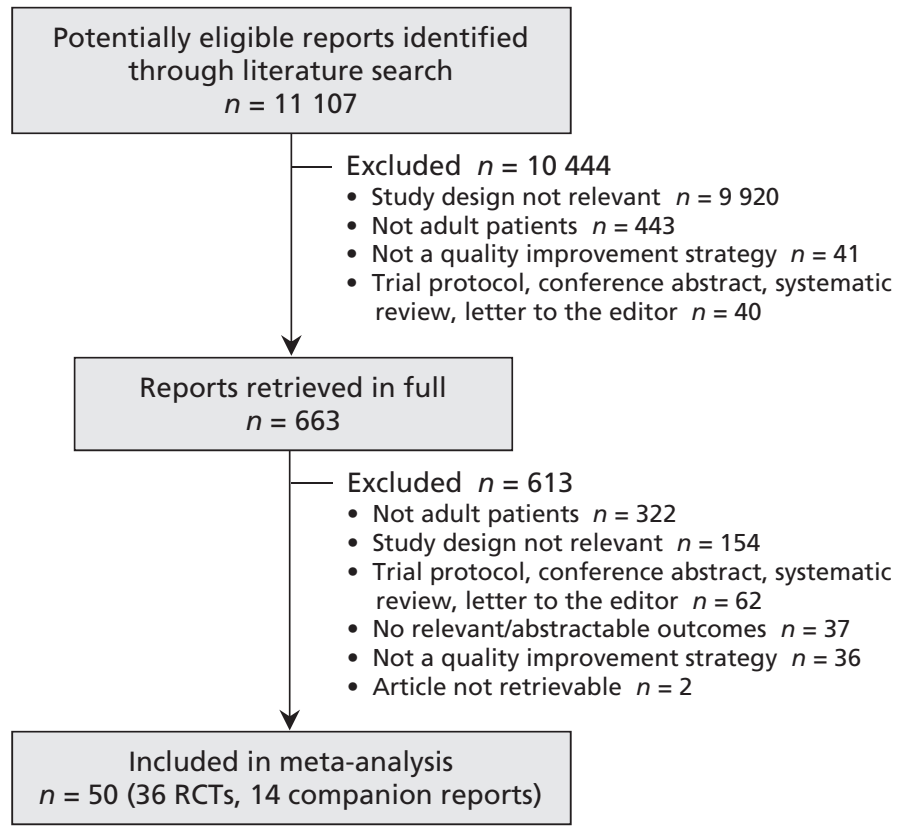

Figure 1: Selection of articles for the meta-analysis. RCT = randomized clinical trial.
N.M.I., H.M.A., P.A.K., E.B., M.G., H.M. or L.K.E.) independently read each article and abstracted the relevant data. Differences in abstraction were resolved by team discussion. Because it is often difficult to classify quality improvement strategies, classification of strategies was performed independently by a systematic review methodologist and a clinician. Conflicts were resolved through discussion. Attempts were made to identify related publications (referred to as companion reports). Study authors were contacted via email for clarification of data if necessary (e.g., unreported standard deviations for continuous data, mean age of included patients).

\section{Appraisal of risk of bias}

We used the Cochrane Effective Practice and Organisation of Care Risk-of-Bias Tool to assess risk of bias. ${ }^{22}$ Each included article was independently appraised by 2 reviewers (A.C.T., N.M.I., H.M.A., P.A.K., E.B., M.G., H.M. or L.K.E.). Conflicts were resolved by discussion or the involvement of a third reviewer (A.C.T. or S.E.S.).

\section{Data synthesis}

We used a random-effects meta-analysis to combine data for outcomes reported in at least 2 RCTs. ${ }^{16}$ Mean differences were calculated for studies reporting the average number of visits per patient per month (i.e., continuous outcomes), and relative risks (RRs) were calculated for studies reporting the proportion of patients with visits (i.e., dichotomous outcomes). Funnel plots were created to identify potential publication bias. ${ }^{23}$

Before conducting the meta-analysis, we examined 3 types of heterogeneity: clinical (e.g., type of patient population, setting), methodologic (e.g., quality improvement strategy examined) and statistical (e.g., $I^{2}$ statistic). ${ }^{24}$ Our approach for dealing with significant heterogeneity was to conduct appropriate subgroup analyses. We conducted post hoc subgroup analyses to determine the influence of the following factors: type of patient (primarily those with mental illness $\mathrm{v}$. those with chronic medical conditions other than mental illness; and age $\geq 65 \mathrm{yr}$ v. $<65 \mathrm{yr}$ ), and type of frequent user based on the RCT eligibility criteria (at risk of being a frequent user = having a history of inpatient care with other predisposing factors, such as multiple comorbidities or psychosocial morbidity; low utilization = "frequent use" defined as 1 to 2 contacts with the health care system in the past year among patients with multiple comorbidities or psychosocial morbidity; moderate utilization $=3$ to 4 contacts with the health care system in the past year; and most frequent/severe utilization $=\geq 5$ contacts with the health care system in the past year). 


\section{Results}

\section{Search results and study characteristics}

Of the 11107 citations identified through the literature search, 663 full-text articles were reviewed. After exclusion of 613 articles for various reasons (Figure 1), we included 36 RCTs (total 7494 patients) ${ }^{25-60}$ plus an additional 14 companion reports. ${ }^{61-74}$

The studies were published between 1987 and 2014 by researchers in North America $(n=24)$, Europe $(n=8)$, Australia $(n=2)$, Israel $(n=1)$ and South Africa $(n=1)$ (Table 1). One study was a cluster RCT. The duration of follow-up ranged from 1 to 36 months.

The definition of a frequent user of health care services varied across the studies. Some studies included patients who were at risk of being frequent users ( $n=11$ studies), whereas others included patients with low utilization $(n=8$ studies), moderate utilization ( $n=2$ studies) or the most frequent/severe utilization ( $n=15$ studies). (Additional study and patient characteristics are shown in Appendix 2, available at www.cmaj. ca/lookup/suppl/doi:10.1503/cmaj.140289/-/DC1). Most of the studies included patients with a primary diagnosis of mental illness; 14 studies included patients with a chronic medical condition other than mental illness (Table 1). Twelve studies included patients with severe mental health conditions, such as schizophrenia and substance abuse disorders, and 12 studies included patients who were homeless. The mean age of participants ranged from 28.1 to 81.6 years. The studies included from $25 \%$ to $77 \%$ women (Appendix 2).

\section{Care coordination strategies}

The following strategies were used to improve care coordination: case management $(n=29$ studies), team changes $(n=21)$, self-management $(n=$ $19)$ and clinical information systems $(n=1)$ (details about the strategies are included in Appendices 3 and 4, available at www.cmaj.ca/lookup /suppl/doi:10.1503/cmaj.140289/-/DC1). The number of quality improvement strategies examined per study ranged from 1 to 5 (median 2.5). The intervention included outreach activities in 23 studies and patient navigators in 6 studies. The comparator group received patient education in 1 study or low-intensity case management in 11 studies involving patients with mental illness.

\section{Risk of bias results}

The risk of bias varied widely across the studies (Table 2; Appendix 5, available at www.cmaj.ca /lookup/suppl/doi:10.1503/cmaj.140289/-/DC1). One study had a high risk of bias on 4 criteria, another had a high risk of bias on 3 criteria, 3 stud- ies had a high risk of bias on 2 criteria, 18 had a high risk of bias on 1 criterion, and the rest of the studies did not have a high risk of bias on any of the criteria. The risk of bias was unclear across many of the criteria. Funnel plots did not reveal evidence of publication bias (data not shown).

\section{Effect on emergency department visits}

After a median duration of 9 months of followup, the proportion of patients who visited emergency departments did not differ significantly between the intervention and control groups (RR $1.11,95 \%$ confidence interval $[\mathrm{CI}] 0.65$ to $1.90 ; 6$ studies; $P^{2}=0.85 \%$ ) (Figure 2; Appendix 6, available at www.cmaj.ca/lookup/suppl/doi:10.1503 /cmaj.140289/-/DC1). The effect was significant only among older patients, with fewer in the intervention group than in the control group visiting emergency departments (RR 0.69, 95\% CI 0.54 to $0.89 ; 2$ studies; $I^{2}=0 \%$ ).

In the analysis of studies that reported the mean number of emergency department visits per patient per month, no difference was found between the intervention and control groups after a median duration of 12 months of follow-up (mean difference $-0.02,95 \% \mathrm{CI}-0.06$ to 0.03 ; 7 studies; $I^{2}=0 \%$ ) (Appendices 6 and 7 , available at www.cmaj.ca/lookup/suppl/doi:10.1503/cmaj $.140289 /$ //DC1). None of the subgroup analyses was statistically significant.

\section{Effect on hospital admissions}

After a median duration of 12 months of followup, significantly fewer patients in the intervention group than in the control group were admitted to hospital (RR $0.81,95 \%$ CI, 0.72 to 0.91 ; 18 studies; $I^{2}=58 \%$ ) (Figure 3; Appendix 6). Specific quality improvement strategies that significantly reduced the number of admissions were case management, team changes, promotion of selfmanagement and patient education. Among patients with chronic conditions other than mental illness, significantly fewer patients in the intervention group than in the control group were admitted to hospital. No difference was found between the intervention and control groups among patients with mental illness or severe mental illness (e.g., schizophrenia and severe bipolar disorder). Interventions that had a significant effect were those with an outreach component and those aimed at patients with the most frequent/severe utilization rate and those at risk of frequent use. Statistically significant results were not observed with interventions that used patient navigators or those aimed at patients with low utilization rates.

In the analysis of studies that reported the mean number of hospital admissions per patient per month, no difference was found between the inter- 
vention and control groups after a median duration of 18 months of follow-up (mean difference 0.00 , $95 \% \mathrm{CI}-0.01$ to $0.01 ; 12$ studies; $I^{2}=0 \%$ ) (Appen- dices 6 and 8, available at www.cmaj.ca/lookup /suppl/doi:10.1503/cmaj.140289/-/DC1). None of the subgroup analyses was statistically significant.

Table 1: Study and patient characteristics

\begin{tabular}{|c|c|c|c|c|c|c|}
\hline Study* & Country & $\begin{array}{c}\text { Quality } \\
\text { improvement } \\
\text { strategy }\end{array}$ & $\begin{array}{l}\text { Patients with } \\
\text { mental illness }\end{array}$ & $\begin{array}{l}\text { Homeless } \\
\text { patients }\end{array}$ & $\begin{array}{c}\text { Age, yr, } \\
\text { mean } \pm \text { SD }\end{array}$ & $\begin{array}{c}\text { Duration of } \\
\text { follow up, mo }\end{array}$ \\
\hline Botha et al., $2014^{25}$ [61] & South Africa & $\mathrm{CM}, \mathrm{TC}$ & Yes $\ddagger$ & Yes & $32.3 \pm 9.9$ & 36 \\
\hline Burns et al., $2014^{26}$ & United States & CM, SM, PE & No & No & NR & 1 \\
\hline Gellis et al., 2014 27 [62] & United States & FR, CM, SM, PE, CE & Yes & No & $79.2 \pm 7.4$ & 12 \\
\hline Ruchlewska et al., $2014^{28}$ & Europe & SM & Yes $\ddagger$ & Yes & $40.0 \pm 11.6$ & 18 \\
\hline Puschner et al., $2011^{29}$ & Europe & TC, SM & Yesł & Yes & $41.3 \pm 11.2$ & 18 \\
\hline Courtney et al., $2009^{30}$ & Australia & CM, TC, SM, PE & Yes & No & $78.8 \pm 6.9$ & 6 \\
\hline Killaspy et al., $2009^{31}[63]$ & Europe & $\mathrm{CM}, \mathrm{TC}$ & Yes & No & $39.0 \pm 11.0$ & 36 \\
\hline Koehler et al., $2009^{32}$ & United States & TC, CM, PE, SM, CIS & No & No & $78.5 \pm 5.5$ & 2 \\
\hline Bellon et al., $2008^{33}$ & Europe & SM, CQI, CE & Yes§ & No & $48.4 \pm N R$ & 15 \\
\hline Lichtenberg et al., $2008^{34}$ & Israel & CM, TC, SM & Yes & No & $28.1 \pm 11.0$ & 12 \\
\hline Shumway et al., $2008^{35}$ & United States & $\mathrm{CM}$ & Yes§ & No & $43.3 \pm 9.5$ & 24 \\
\hline Rivera et al., $2007^{36}$ & United States & $\mathrm{CM}$ & Yes $\ddagger$ & Yes & $38.3 \pm 12.8$ & 12 \\
\hline Schreuders et al., $2007^{37}[64,65]$ & Europe & CM, SM & Yes & No & $52.9 \pm 14.8$ & 3 \\
\hline Sledge et al., $2006^{38}$ & United States & CM, TC, SM & No & No & $51.0 \pm 52.8$ & 12 \\
\hline Scott et al., $2004^{39}[66]$ & United States & TC, PE & No & No & $74.2 \pm 7.5$ & 24 \\
\hline Castro et al., $2003^{40}$ & United States & CM, PE, SM & No & No & $36.4 \pm 11.5$ & 12 \\
\hline Laramee et al., $2003^{41}$ & United States & $\mathrm{CM}, \mathrm{TC}, \mathrm{PE}, \mathrm{SM}$ & No & No & $70.7 \pm 11.8$ & 2 \\
\hline Harrison-Read et al., $2002^{42}$ & Europe & CM, TC, SM & Yesł & Yes & $39.2 \pm 39.2$ & 24 \\
\hline Kasper et al., $2002^{43}$ & United States & CM, TC, PE, SM, FI & No & No & $61.9 \pm 13.4$ & 6 \\
\hline Katzelnick et al., $2000^{44[67]}$ & United States & $\mathrm{CM}, \mathrm{PE}, \mathrm{CE}$ & Yes & No & $45.5 \pm N R$ & 12 \\
\hline Burns $1999^{45}[68-71]$ & Europe & $\mathrm{CM}, \mathrm{TC}, \mathrm{PE}$ & Yesł & Yes & $38.3 \pm 11.7$ & 24 \\
\hline Coleman et al., $1999^{46} \dagger$ & United States & $\mathrm{CM}$ & No & No & $77.3 \pm N R$ & 24 \\
\hline Gagnon et al., 199947 & Canada & TC, SM, CE & No & No & $81.6 \pm 6.5$ & 10 \\
\hline Salkever et al., $1999^{48}$ & United States & $\mathrm{CM}$ & Yes‡ & Yes & $35.7 \pm N R$ & 18 \\
\hline Essock et al., $1998^{49}[72]$ & United States & CM, TC & Yesł & Yes & $41.0 \pm N R$ & 18 \\
\hline Stewart et al., $1998^{50}$ & Australia & $\mathrm{TC}, \mathrm{CM}, \mathrm{PE}, \mathrm{SM}$ & No & No & $75.0 \pm 10.5$ & 6 \\
\hline Beck et al., $1997^{51}$ & United States & $\mathrm{TC}, \mathrm{PE}, \mathrm{FR}$ & No & NA & $73.5 \pm N R$ & 12 \\
\hline Spillane et al., $1997^{52}$ & United States & $\mathrm{TC}$ & No & No & $38.5 \pm 48.2$ & 12 \\
\hline Lafave et al., $1996^{53}$ & Canada & CM, TC, SM & Yes & No & $35.8 \pm 2.0$ & 12 \\
\hline Quinlivan et al., $1995^{54}$ & United States & $\mathrm{CM}$ & Yesł & Yes & NR & 24 \\
\hline Rich et al., $1995^{55}$ [73] & United States & $\mathrm{CM}, \mathrm{TC}, \mathrm{PE}, \mathrm{SM}$ & No & No & $79.2 \pm 6.0$ & 3 \\
\hline Rosenheck et al., $1995^{56}$ [74] & United States & $\mathrm{CM}, \mathrm{TC}$ & Yesł & Yes & NR & 24 \\
\hline Muijen et al., $1994^{57}$ & Europe & $\mathrm{CM}$ & Yesł & Yes & $37.0 \pm 11.0$ & 18 \\
\hline Rich et al., $1993^{58}$ & United States & TC, CM, PE, SM & No & No & $79.0 \pm 6.2$ & 3 \\
\hline Bond et al., $1988^{59}$ & United States & $\mathrm{CM}$ & Yes & No & $34.5 \pm N R$ & 6 \\
\hline Franklin et al., $1987^{60}$ & United States & $\mathrm{CM}$ & Yesł & Yes & NR & 12 \\
\hline
\end{tabular}




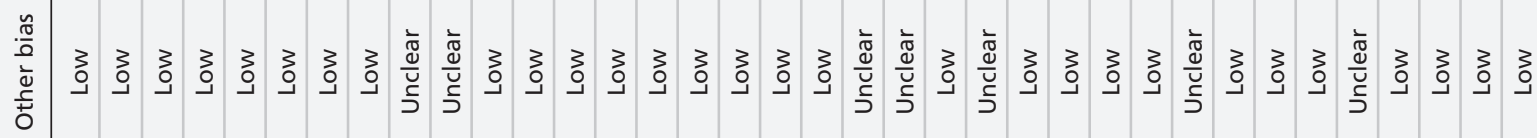

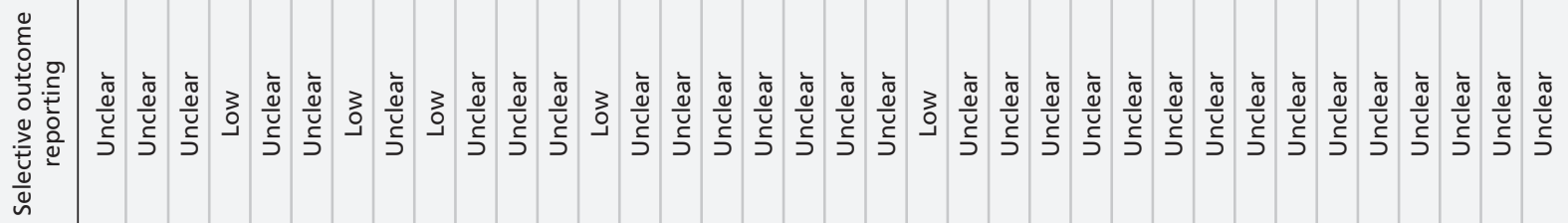

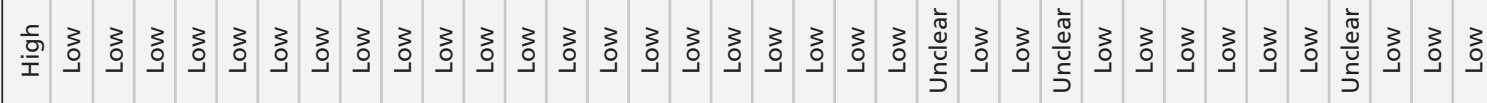

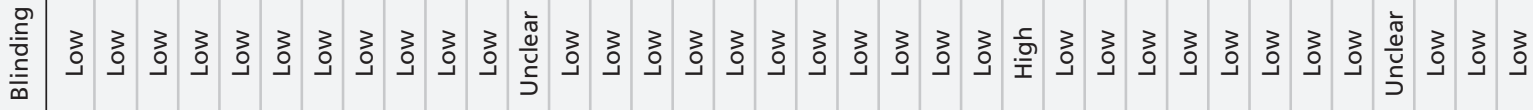

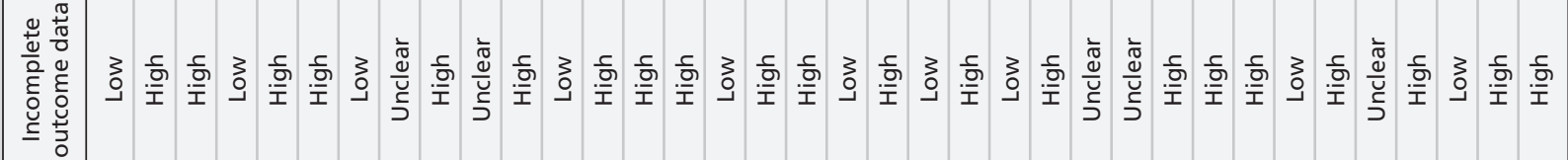
寡

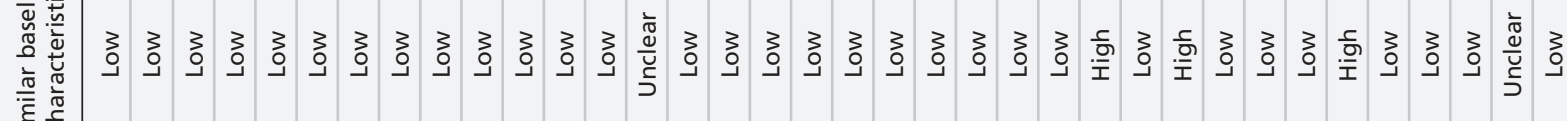

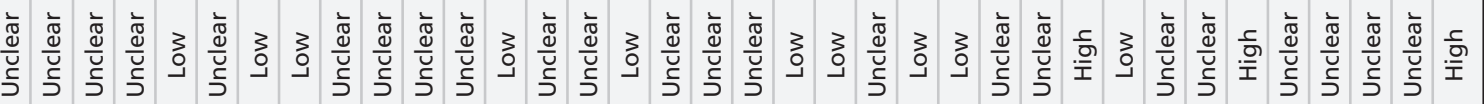

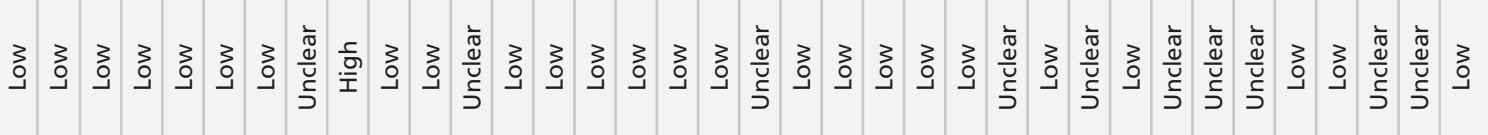
毫 


\section{Effect on clinic visits}

After a median duration of 12 months of followup, the proportion of patients who made clinic visits did not differ significantly between the intervention and control groups (RR 0.86, 95\% CI 0.58 to $1.27 ; 5$ studies; $I^{2}=91 \%$ ) (Appendix 6). None of the subgroup analyses was statistically significant.

There was also no difference in the mean number of clinic visits per patient per month between the 2 groups after a median of 12 months of followup (mean difference $-0.08,95 \%$ CI -0.23 to 0.06 ; 11 studies; $P=65 \%$ ) (Appendices 6 and 9, available at www.cmaj.ca/lookup/suppl/doi:10.1503 /cmaj.140289/-/DC1). None of the subgroup analyses was statistically significant.

\section{Effect on length of stay}

After a median duration of 12 months of followup, the mean number of days in hospital per patient per month did not differ significantly between the intervention and control groups (mean difference $-0.09,95 \%$ CI -0.26 to $0.09 ; 19$ studies; $P=0 \%$ ) (Appendices 6 and 10, available at www.cmaj.ca/lookup/suppl/doi:10.1503/cmaj $.140289 /$ /DC1). None of the subgroup analyses was statistically significant.

\section{Interpretation}

We found that quality improvement strategies focused on the coordination of care reduced hospital admissions among patients with chronic conditions other than mental illness and reduced emergency department visits among older patients. The strategies were not effective in reducing the use of health care services among patients with mental illness. This lack of effect may have been because 7 of the 11 studies involving patients with mental illness had a care coordination strategy (a form of case management) as part of their control intervention.

Of the interventions examined, team changes, case management and promotion of selfmanagement had significant effects on reducing hospital admissions. Patient education, which is not one of the care-coordination quality improvement strategies based on Wagner's model, ${ }^{16}$ also significantly reduced hospital admissions. Patient education and promotion of self-management are likely less resource intensive than case management interventions are, ${ }^{17}$ which suggests that quality improvement strategies targeting patients (as opposed to clinicians) might be an efficient use of resources. Indeed, in other systematic reviews, patient education and promotion of self-management were found to be highly effective in improving diabetes care. ${ }^{75,76}$

A previous systematic review assessed the effect of various interventions on frequent users and found that case management and multidisciplinary teams were likely effective in reducing emergency department visits. ${ }^{14}$ The authors did not conduct a meta-analysis or examine utilization beyond the emergency department. We observed statistically significant reductions in emergency department visits among older patients, but not specifically for interventions involving case management or team changes.

\section{Limitations}

We identified several limitations in the literature included in our analysis. First, similar to other studies of complex interventions, ${ }^{77}$ studies included in our meta-analysis reported few details about the intensity and "dose" of quality im-

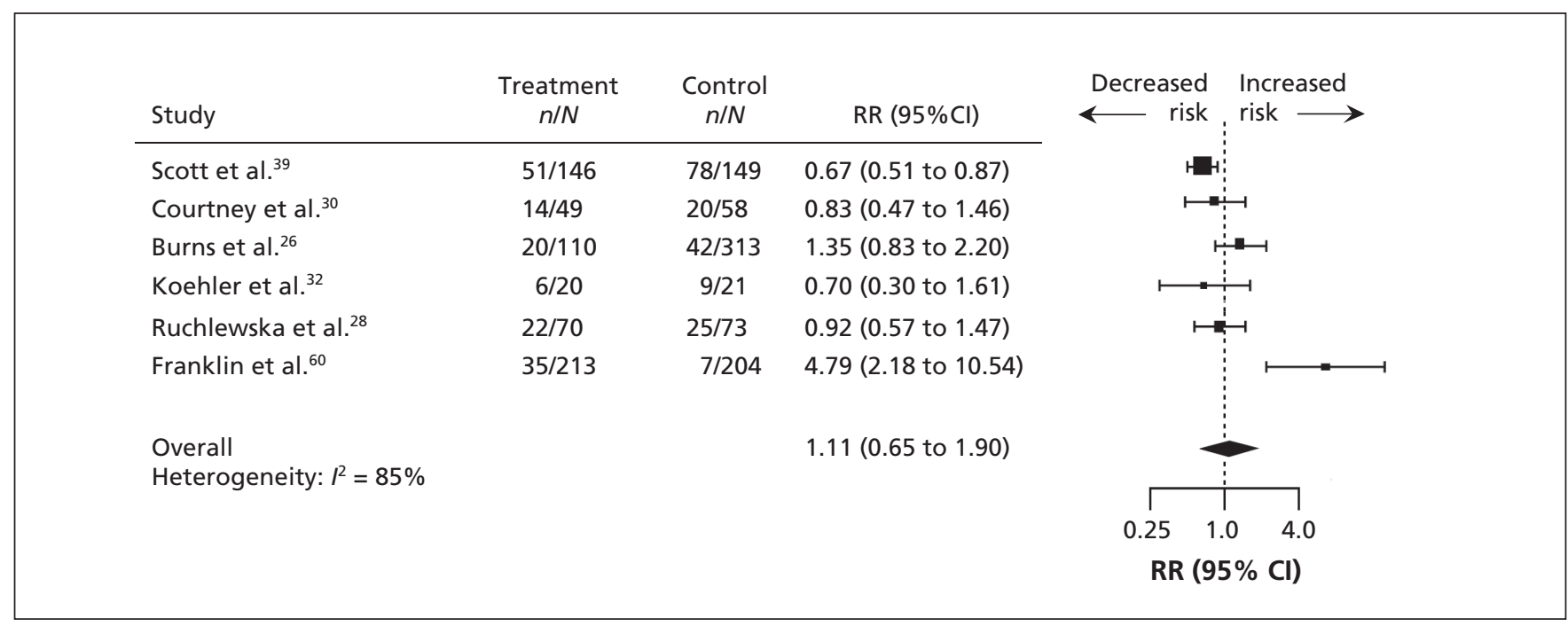

Figure 2: Effect of quality improvement strategies for coordination of care on emergency department visits. Relative risks less than 1.0 indicate a decreased risk of an emergency department visit. $\mathrm{Cl}=$ confidence interval, $\mathrm{RR}=$ relative risk. 


\begin{tabular}{|c|c|c|c|c|c|}
\hline Study & $\begin{array}{c}\text { Treatment } \\
n / N\end{array}$ & $\begin{array}{l}\text { Control } \\
n / N\end{array}$ & $\operatorname{RR}(95 \% \mathrm{Cl})$ & $\begin{array}{r}\text { Decreased } \\
\leftarrow \quad \text { risk }\end{array}$ & $\begin{array}{l}\text { Increased } \\
\text { risk } \longrightarrow\end{array}$ \\
\hline Beck et al. ${ }^{51}$ & $35 / 160$ & $47 / 161$ & 0.75 (0.51 to 1.09$)$ & $\mapsto$ & \\
\hline Botha et al. ${ }^{25}$ & $13 / 32$ & $18 / 24$ & 0.54 (0.34 to 0.87$)$ & $\longmapsto$ & \\
\hline Burns et al. ${ }^{45}$ & $210 / 353$ & $228 / 355$ & 0.93 (0.82 to 1.04$)$ & & \\
\hline Franklin et al. ${ }^{60}$ & $62 / 213$ & $38 / 204$ & 1.56 (1.10 to 2.23 ) & & -1 \\
\hline Lafave et al. ${ }^{53}$ & $13 / 24$ & $37 / 41$ & 0.60 (0.41 to 0.88$)$ & & \\
\hline Puschner et al. ${ }^{29}$ & $108 / 241$ & $103 / 250$ & 1.09 (0.89 to 1.33$)$ & & -4 \\
\hline Rich et al. ${ }^{55}$ & $41 / 142$ & $59 / 140$ & 0.69 (0.50 to 0.95$)$ & & \\
\hline Salkever et al. ${ }^{48}$ & $27 / 91$ & $25 / 53$ & 0.63 (0.41 to 0.96$)$ & & \\
\hline Rich et al. ${ }^{58}$ & $21 / 63$ & $16 / 35$ & $0.73(0.44$ to 1.20$)$ & & \\
\hline Kasper et al. ${ }^{43}$ & $47 / 102$ & $55 / 98$ & 0.82 (0.62 to 1.08$)$ & $r$ & \\
\hline Courtney et al..$^{30}$ & $13 / 49$ & $27 / 58$ & 0.57 (0.33 to 0.98$)$ & 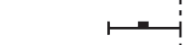 & \\
\hline Castro et al. ${ }^{40}$ & $20 / 50$ & $25 / 46$ & 0.74 (0.48 to 1.13$)$ & $\mapsto$ & \\
\hline Burns et al. ${ }^{26}$ & $17 / 110$ & $56 / 313$ & 0.86 (0.53 to 1.42$)$ & $\mapsto$ & 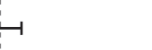 \\
\hline Koehler et al. ${ }^{32}$ & $6 / 20$ & $9 / 21$ & $0.70(0.30$ to 1.61$)$ & $\longmapsto$ & $\longrightarrow$ \\
\hline Ruchlewska et al. ${ }^{28}$ & $24 / 70$ & $33 / 73$ & $0.76(0.50$ to 1.14$)$ & 1 & \\
\hline Laramee et al. ${ }^{41}$ & $49 / 131$ & $46 / 125$ & $1.02(0.74$ to 1.40$)$ & & -1 \\
\hline Stewart et al. ${ }^{50}$ & $24 / 49$ & $31 / 48$ & 0.76 (0.53 to 1.08$)$ & 1 & \\
\hline Lichtenberg et al. ${ }^{34}$ & $71 / 122$ & $74 / 95$ & $0.75(0.62$ to 0.90$)$ & $=$ & \\
\hline \multirow{3}{*}{$\begin{array}{l}\text { Overall } \\
\text { Heterogeneity: } R^{2}=58 \%\end{array}$} & & & 0.81 (0.72 to 0.91$)$ & $\diamond$ & \\
\hline & & & & 025 & 40 \\
\hline & & & & \multicolumn{2}{|c|}{$\operatorname{RR}(95 \% \mathrm{Cl})$} \\
\hline
\end{tabular}

Figure 3: Effect of quality improvement strategies for coordination of care on hospital admissions. Relative risks less than 1.0 indicate a decreased risk of admission to hospital. $\mathrm{Cl}=$ confidence interval, $\mathbf{R R}=$ relative risk.

provement strategies, as well as further details regarding delivery. The Standards for Quality Improvement Reporting Excellence (SQUIRE) guidelines have been developed to improve the reporting of quality improvement strategies, ${ }^{78}$ which will be of benefit to future meta-analyses such as ours. Second, in some studies, the duration of intervention may have been too short (e.g., $1 \mathrm{mo}$ ) to show any significant impact. Third, the duration of follow-up (as little as $3 \mathrm{mo}$ ) was also short in some studies. Fourth, the definition of a frequent user was inconsistent across the studies. Finally, most of the included studies had unclear or inadequate concealment of the allocation sequence and a high risk of bias owing to incomplete outcome data.

Our systematic review process also had some limitations. First, although we searched for unpublished studies, none was identified. However, the funnel plots compiled for the metaanalyses of more than 10 RCTs showed no evidence of publication bias.

Second, this was a challenging area to search, and many of the included studies did not use adequate search terms to allow their identifi- cation. We conducted supplementary searches to surmount this issue (e.g., forward citation searches, manual searches of related articles), but we may have missed relevant studies.

Third, our analysis was limited because the quality improvement strategies were complex and difficult to classify consistently. For example, some of the strategies were interconnected, such as patient education and promotion of selfmanagement, or case management and team changes. However, we conducted a sensitivity analysis of our classification of the strategies, and our results did not change.

Fourth, because of the dearth of data, we were unable to perform more sophisticated analyses, such as meta-regression analysis. As such, we did not control for all potential confounding factors or effect modifiers. Also, there was a small number of studies included for some outcomes (e.g., emergency department visits, clinic visits), which may have led to the nonsignificant effect. As well, the results of the subgroup analyses should be interpreted with caution because of the risk of type 2 statistical error owing to the small number of studies included. 
Fifth, many of the meta-analyses had substantial heterogeneity, which was to be expected given the number of quality improvement strategies assessed, the variety of patient populations examined and the inconsistent definitions of usual care used across the studies. The high heterogeneity may indicate that the results should be interpreted with caution; however, heterogeneity was substantially lower in most of the subgroup analyses (e.g., by type of quality improvement strategy).

Sixth, we did not examine patient-centred outcomes, such as patient experience and quality of life, because the target for our research was health system outcomes.

Seventh, we were unable to examine contextual factors that would have been relevant to our objective, such as socioeconomic status, appropriateness of care and access to a primary care physician, because they were not measured consistently across the studies.

Finally, we abstracted some data on costs but were unable to summarize this in a meaningful manner, because this information varied widely by context.

\section{Conclusion}

We found that quality improvement strategies focused on the coordination of care reduced hospital admissions among patients with chronic conditions other than mental illness and reduced emergency department visits among older patients. Novel strategies are required for patients with mental health conditions. Researchers who are developing and implementing interventions targeted to frequent users should consider specific strategies, such as team changes, case management and promotion of self-management, because these approaches appear to be more effective than other quality improvement strategies in reducing health care utilization. Further research is needed to determine how to optimize care coordination strategies for specific patient subgroups and settings.

\section{References}

1. Mandelberg JH, Kuhn RE, Kohn MA. Epidemiologic analysis of an urban, public emergency department's frequent users. Acad Emerg Med 2000;7:637-46.

2. Hansagi H, Olsson M, Sjoberg S, et al. Frequent use of the hospital emergency department is indicative of high use of other health care services. Ann Emerg Med 2001;37:561-7.

3. Gordon JA, Chudnofsky CR, Hayward RA. Where health and welfare meet: social deprivation among patients in the emergency department. J Urban Health 2001;78:104-11.

4. Hunt KA, Weber EJ, Showstack JA, et al. Characteristics of frequent users of emergency departments. Ann Emerg Med 2006; $48: 1-8$.

5. Williams ER, Guthrie E, Mackway-Jones K, et al. Psychiatric status, somatisation, and health care utilization of frequent attenders at the emergency department: a comparison with routine attenders. J Psychosom Res 2001;50:161-7.

6. Sun BC, Burstin HR, Brennan TA. Predictors and outcomes of frequent emergency department users. Acad Emerg Med 2003; 10:320-8.

7. Gunnarsdottir OS, Rafnsson V. Mortality of the users of a hospital emergency department. Emerg Med J 2006;23:269-73.

8. Derlet RW, Richards JR. Overcrowding in the nation's emergency departments: complex causes and disturbing effects. Ann Emerg Med 2000;35:63-8.

9. Chambers C, Chiu S, Katic M, et al. High utilizers of emergency health services in a population-based cohort of homeless adults. Am J Public Health 2013;103(Suppl2):S302-10.

10. Moe J, Bailey AL, Oland R, et al. Defining, quantifying, and characterizing adult frequent users of a suburban Canadian emergency department. CJEM 2013;15:1-13.

11. Fisher S, Stevens RF. Subgroups of frequent users of an inpatient mental health program at a community hospital in Canada. Psychiatr Serv 1999;50:244-7.

12. Demers M. Frequent users of ambulatory health care in Quebec: the case of doctor-shoppers. CMAJ 1995;153:37-42.

13. Pines JM, Asplin BR, Kaji AH, et al. Frequent users of emergency department services: gaps in knowledge and a proposed research agenda. Acad Emerg Med 2011;18:e64-9.

14. Althaus F, Paroz S, Hugli O, et al. Effectiveness of interventions targeting frequent users of emergency departments: a systematic review. Ann Emerg Med 2011;58:41-52 e42.

15. Sampson M, McGowan J, Cogo E, et al. An evidence-based practice guideline for the peer review of electronic search strategies. J Clin Epidemiol 2009;62:944-52.

16. Barr VJ, Robinson S, Marin-Link B, et al. The expanded Chronic Care Model: an integration of concepts and strategies from population health promotion and the Chronic Care Model. Hosp Q 2003;7:73-82.

17. Tricco AC, Ivers NM, Grimshaw JM, et al. Effectiveness of quality improvement strategies on the management of diabetes: a systematic review and meta-analysis. Lancet 2012;379:2252-61

18. Shojania KG, Ranji SR, McDonald KM, et al. Effects of quality improvement strategies for type 2 diabetes on glycemic control: a meta-regression analysis. JAMA 2006;296:427-40.

19. McDonald KM, Sundaram V, Bravata DM, et al. Closing the quality gap: a critical analysis of quality improvement strategies (Vol 7: Care coordination). Rockville (MD): Agency for Healthcare Research and Quality; 2007.

20. Shojania KG, Ranji SR, Shaw LK, et al. Closing the quality gap: a critical analysis of quality improvement strategies (Vol 2 . Diabetes care). Rockville (MD): Agency for Healthcare Research and Quality; 2004.

21. Walkinshaw E. Patient navigators becoming the norm in Canada. CMAJ 2011;183:E1109-10.

22. Suggested risk of bias criteria for EPOC reviews. Ottawa: Cochrane Effective Practice and Organisation of Care Group; 2012. Available: http://epoc.cochrane.org/sites/epoc.cochrane .org/files/uploads/Suggested $\% 20$ risk $\% 20$ of $\% 20$ bias $\% 20$ criteria $\%$ 20for\%20EPOC\%20reviews.pdf (accessed 2014 Aug 21).

23. Egger M, Davey Smith G, Schneider M, et al. Bias in metaanalysis detected by a simple, graphical test. BMJ 1997;315: 629-34.

24. Higgins JP, Thompson SG. Quantifying heterogeneity in a metaanalysis. Stat Med 2002;21:1539-58.

25. Botha UA, Koen L, Galal U, et al. The rise of assertive community interventions in South Africa: a randomized control trial assessing the impact of a modified assertive intervention on readmission rates; a three year follow-up. BMC Psychiatry 2014; 14:56.

26. Burns ME, Galbraith AA, Ross-Degnan D, et al. Feasibility and evaluation of a pilot community health worker intervention to reduce hospital readmissions. Int J Qual Health Care 2014; 26:358-65.

27. Gellis ZD, Kenaley BL, Ten Have T. Integrated telehealth care for chronic illness and depression in geriatric home care patients: the Integrated Telehealth Education and Activation of Mood (I-TEAM) study. J Am Geriatr Soc 2014;62:889-95.

28. Ruchlewska A, Wierdsma AI, Kamperman AM, et al. Effect of crisis plans on admissions and emergency visits: a randomized controlled trial. PLoS ONE 2014;9:e91882.

29. Puschner B, Steffen S, Volker KA, et al. Needs-oriented discharge planning for high utilisers of psychiatric services: multicentre randomised controlled trial. Epidemiol Psychiatr Sci 2011;20:181-92.

30. Courtney M, Edwards H, Chang A, et al. Fewer emergency readmissions and better quality of life for older adults at risk of hospital readmission: a randomized controlled trial to determine the effectiveness of a 24-week exercise and telephone follow-up program. J Am Geriatr Soc 2009;57:395-402.

31. Killaspy $\mathrm{H}$, Kingett $\mathrm{S}$, Bebbington $\mathrm{P}$, et al. Randomised evaluation of assertive community treatment: 3-year outcomes. $\mathrm{Br} \mathrm{J}$ Psychiatry 2009;195:81-2. 
32. Koehler BE, Richter KM, Youngblood L, et al. Reduction of 30-day postdischarge hospital readmission or emergency department (ED) visit rates in high-risk elderly medical patients through delivery of a targeted care bundle. J Hosp Med 2009;4: 211-8.

33. Bellón JA, Rodriguez-Bayon A, de Dios Luna J, et al. Successful GP intervention with frequent attenders in primary care: randomised controlled trial. Br J Gen Pract 2008;58:324-30.

34. Lichtenberg P, Levinson D, Sharshevsky Y, et al. Clinical case management of revolving door patients - a semi-randomized study. Acta Psychiatr Scand 2008;117:449-54.

35. Shumway M, Boccellari A, O'Brien K, et al. Cost-effectiveness of clinical case management for ED frequent users: results of a randomized trial. Am J Emerg Med 2008;26:155-64.

36. Rivera JJ, Sullivan AM, Valenti SS. Adding consumer-providers to intensive case management: Does it improve outcome? Psychiat Serv 2007:58:802-9.

37. Schreuders B, van Marwijk H, Smit J, et al. Primary care patients with mental health problems: outcome of a randomised clinical trial. Br J Gen Pract 2007:57:886-91.

38. Sledge WH, Brown KE, Levine JM, et al. A randomized trial of primary intensive care to reduce hospital admissions in patients with high utilization of inpatient services. Dis Manage 2006;9: 328-38.

39. Scott JC, Conner DA, Venohr I, et al. Effectiveness of a group outpatient visit model for chronically ill older health maintenance organization members: a 2-year randomized trial of the cooperative health care clinic. J Am Geriatr Soc 2004;52:1463-70

40. Castro M, Zimmermann NA, Crocker S, et al. Asthma intervention program prevents readmissions in high healthcare users. Am J Respir Crit Care Med 2003;168:1095-9.

41. Laramee AS, Levinsky SK, Sargent J, et al. Case managemen in a heterogeneous congestive heart failure population: a randomized controlled trial. Arch Intern Med 2003;163:809-17.

42. Harrison-Read P, Lucas B, Tyrer P, et al. Heavy users of acute psychiatric beds: randomized controlled trial of enhanced community management in an outer London borough. Psychol Med 2002;32:403-16.

43. Kasper EK, Gerstenblith G, Hefter G, et al. A randomized tria of the efficacy of multidisciplinary care in heart failure outpatients at high risk of hospital readmission. J Am Coll Cardiol 2002;39:471-80.

44. Katzelnick DJ, Simon GE, Pearson SD, et al. Randomized trial of a depression management program in high utilizers of medical care. Arch Fam Med 2000;9:345-51.

45. Burns T, Creed F, Fahy T, et al. Intensive versus standard case management for severe psychotic illness: a randomised trial. UK 700 Group. Lancet 1999;353:2185-9.

46. Coleman EA, Grothaus LC, Sandhu N, et al. Chronic care clinics: a randomized controlled trial of a new model of primary care for frail older adults. J Am Geriatr Soc 1999;47:775-83.

47. Gagnon AJ, Schein C, McVey L, et al. Randomized controlled trial of nurse case management of frail older people. J Am Geriatr Soc 1999;47:1118-24.

48. Salkever D, Domino ME, Burns BJ, et al. Assertive community treatment for people with severe mental illness: the effect on hospital use and costs. Health Serv Res 1999;34:577-601.

49. Essock SM, Frisman LK, Kontos NJ. Cost-effectiveness of assertive community treatment teams. Am J Orthopsychiatry 1998;68:179-90.

50. Stewart S, Pearson S, Horowitz JD. Effects of a home-based intervention among patients with congestive heart failure discharged from acute hospital care. Arch Intern Med 1998;158:1067-72.

51. Beck A, Scott J, Williams P, et al. A randomized trial of group outpatient visits for chronically ill older HMO members: the Cooperative Health Care Clinic. J Am Geriatr Soc 1997;45:543-9.

52. Spillane LL, Lumb EW, Cobaugh DJ, et al. Frequent users of the emergency department: Can we intervene? Acad Emerg Med 1997; 4:574-80.

53. Lafave HG, de Souza HR, Gerber GJ. Assertive community treatment of severe mental illness: a Canadian experience. Psychiatr Serv 1996;47:757-9.

54. Quinlivan R, Hough R, Crowell A, et al. Service utilization and costs of care for severely mentally ill clients in an intensive case management program. Psychiatr Serv 1995;46:365-71.

55. Rich MW, Beckham V, Wittenberg C, et al. A multidisciplinary intervention to prevent the readmission of elderly patients with congestive heart failure. $N$ Engl J Med 1995;333:1190-5.

56. Rosenheck R, Neale M, Leaf P, et al. Multisite experimental cost study of intensive psychiatric community care. Schizophr Bull 1995;21:129-40.

57. Muijen M, Cooney M, Strathdee G, et al. Community psychiatric nurse teams: intensive support versus generic care. Br J Psychiatry 1994;165:211-7.
58. Rich MW, Vinson JM, Sperry JC, et al. Prevention of readmission in elderly patients with congestive heart failure: results of a prospective, randomized pilot study. J Gen Intern Med 1993;8: 585-90.

59. Bond GR, Miller LD, Krumwied RD, et al. Assertive case management in three CMHCs: a controlled study. Hosp Community Psychiatry 1988;39:411-8.

60 Franklin JL, Solovitz B, Mason M, et al. An evaluation of case management. Am J Public Health 1987;77:674-8.

61. Botha UA, Koen L, Joska JA, et al. Assessing the efficacy of a modified assertive community-based treatment programme in a developing country. BMC Psychiatry 2010;10:73.

62. Gellis ZD, Kenaley B, McGinty J, et al. Outcomes of a telehealth intervention for homebound older adults with heart or chronic respiratory failure: a randomized controlled trial. Gerontologist 2012;52:541-52.

63. Killaspy H, Bebbington P, Blizard R, et al. The REACT study: randomised evaluation of assertive community treatment in north London. BMJ 2006;332:815-20.

64. Schreuders B, van Oppen P, van Marwijk HW, et al. Frequen attenders in general practice: problem solving treatment provided by nurses. BMC Fam Pract 2005;6:42.

65. Bosmans JE, Schreuders B, van Marwijk HW, et al. Costeffectiveness of problem-solving treatment in comparison with usual care for primary care patients with mental health problems: a randomized trial. BMC Fam Pract 2012;13:98.

66. Coleman EA, Eilertsen TB, Kramer AM, et al. Reducing emergency visits in older adults with chronic illness: a randomized, controlled trial of group visits. Effect Clin Pract 2001;4:49-57.

67. Simon GE, Manning WG, Katzelnick DJ, et al Costeffectiveness of systematic depression treatment for high utilizers of general medical care. Arch Gen Psychiatry 2001;58:181-7.

68. Cost-effectiveness of intensive $\mathrm{v}$. standard case management for severe psychotic illness. UK700 case management trial. UK700 Group. Br J Psychiatry 2000;176:537-43.

69. Burns T, Fiander M, Kent A, et al. Effects of case-load size on the process of care of patients with severe psychotic illness. Report from the UK700 trial. Br J Psychiatry 2000;177:427-33.

70. Burns T, White I, Byford S, et al. Exposure to case management: relationships to patient characteristics and outcome. Report from the UK700 trial. Br J Psychiatry 2002;181:236-41.

71. Hassiotis A, Ukoumunne OC, Byford S, et al. Intellectual functioning and outcome of patients with severe psychotic illnes randomised to intensive case management. Report from the UK700 trial. Br J Psychiatry 2001;178:166-71.

72. Essock SM, Mueser KT, Drake RE, et al. Comparison of ACT and standard case management for delivering integrated treatment for co-occurring disorders. Psychiatr Serv 2006;57:185-96.

73. Rich MW, Gray DB, Beckham V, et al. Effect of a multidisciplinary intervention on medication compliance in elderly patients with congestive heart failure. Am J Med 1996;101:270-6.

74. Rosenheck RA, Neale MS. Cost-effectiveness of intensive psychiatric community care for high users of inpatient services. Arch Gen Psychiatry 1998;55:459-66.

75. McKay MP, Vaca FE, Field C, et al. Public health in the emergency department: overcoming barriers to implementation and dissemination. Acad Emerg Med 2009;16:1132-7.

76. Prior M, Guerin M, Grimmer-Somers K. The effectiveness of clinical guideline implementation strategies - a synthesis of systematic review findings. J Eval Clin Pract 2008;14:888-97.

77. Shepperd S, Lewin S, Straus S, et al. Can we systematically review studies that evaluate complex interventions? PLoS Med 2009;6:e1000086.

78. Davidoff F, Batalden PB, Stevens DP, et al. Development of the SQUIRE publication guidelines: evolution of the SQUIRE project. Jt Comm J Qual Patient Saf 2008;34:681-7.

Affiliations: Li Ka Shing Knowledge Institute (Tricco, Antony, Ashoor, Khan, Blondal, Ghassemi, MacDonald, Chen, Ezer, Straus), St. Michael's Hospital, Toronto, Ont.; Division of Epidemiology (Tricco), Dalla Lana School of Public Health, University of Toronto, Toronto, Ont.; Women's College Hospital (Ivers), Toronto, Ont.; Departments of Family and Community Medicine (Ivers) and of Geriatric Medicine (Straus), University of Toronto, Toronto, Ont.

Contributors: Andrea Tricco contributed to the study concept and design, helped obtain funding for the study, screened citations and full-text articles, abstracted data, helped analyze the data and interpreted the results. Jesmin Antony screened full-text articles, abstracted data and appraised study quality. Noah Ivers abstracted data, 
appraised study quality and interpreted the results. Huda Ashoor abstracted data and appraised study quality. Paul Khan, Erik Blondal and Marco Ghassemi screened citations, abstracted data and appraised study quality. Lianne Ezer screened citations and abstracted data. Heather MacDonald screened citations and full-text articles and abstracted data. Sharon Straus contributed to the study concept and design, helped obtain the funding and interpreted the results. Andrea Tricco and Sharon Straus drafted the manuscript, Lianne Ezer helped write the background section and introduction, and all of the authors critically revised the manuscript and accepted the final version submitted for publication. All of authors had full access to all of the data in the study and take responsibility for the integrity of the data and the accuracy of the analyses.

Funding: This project was funded by the Building Bridges to Integrate Care (BRIDGES) initiative, through the Ontario Min- istry of Health and Long-Term Care. The funding group had no role in the study design, the collection and analysis of data, the decision to publish or the preparation of the manuscript.

Andrea Tricco is funded by a Canadian Institutes of Health Research/Drug Safety and Effectiveness Network (CIHR/DSEN) New Investigator Award on Knowledge Synthesis Methodology. Noah Ivers holds fellowship awards from the CIHR and from the Department of Family and Community Medicine, University of Toronto. Sharon Straus is funded by a CIHR Tier 1 Research Chair in Knowledge Translation.

Acknowledgements: The authors thank Laure Perrier for conducting, and Becky Skidmore for peer reviewing, the literature search; Mariam Tashkandi, Erin Lillie and Charlene Soobiah for screening some of the citations; Jennifer D'Souza for locating full-text articles; and Wing Hui and Judy Tran for formatting the tables and text in the submitted manuscript. 